\title{
Creating a common Danish list of railway timetable evaluation criteria and revising the timetabling process accordingly
}

\author{
B. Schittenhelm ${ }^{1,2}$ \& A. Landex ${ }^{1}$ \\ ${ }^{1}$ Department of Transport, Technical University of Denmark, Denmark \\ ${ }^{2}$ Department of Traffic Planning, Rail Net Denmark, Denmark
}

\begin{abstract}
With the liberalization of the European railway sector, the number of national railway timetable stakeholders has increased drastically. A need arises for reaching a common consensus about the timetabling criteria and their priority which the timetabling process should be based on.

To create a common Danish list of railway timetable evaluation and optimization criteria a two step process was launched. Individual interviews were conducted with selected Danish stakeholders: DSB, Arriva, DB Schenker Rail, The Danish Transport Authority and Rail Net Denmark. Each stakeholder made a list of five prioritized timetabling criteria. These lists were input for the second working step: A timetabling criteria workshop at the Technical University of Denmark, where a first agreement on timetabling criteria between stakeholders was achieved. The result was a three layered list of prioritized criteria. Rank 1 criteria: capacity consumption on line sections and systematic timetable. Rank 2 criteria: robustness of the timetable and societal acceptance of the timetable and rank 3 criteria: travel time of trains and attractive transfer options.

With this new tool a revised timetabling process at Rail Net Denmark is proposed. The very basic structure of the process cannot be changed due to EU legislation and Rail Net Europe guidelines. Key performance indicators derived from the identified timetabling criteria are introduced. As is a more iterative approach to the timetabling process due to the assumption of major improvements within timetable planning systems. This new iterative timetabling process using key performance indicators will result in improved future timetables and in lower levels of disagreement between timetable stakeholders. Keywords: railway timetables, timetabling criteria, timetable evaluation, timetable key performance indicators, timetabling process.
\end{abstract}




\section{Introduction}

The Danish railway sector has undergone a rapid development during the last 15 years. This was started by the European Union (EU) directive 91/440/EC setting up the road map for the liberalization of railway sectors in EU member states. Beginning January 1997, DSB (Danish State Railways) was divided into a train operating company (TOC) and an infrastructure manager (IM) part. Based on valid EU legislation a separate railway transport authority was created in 2003. Within six years the railway sector went from having one national player to more than four stakeholders, each working with timetabling. See Figure 1 for a time line overview, where boxes with grey filling are EU legislation milestones and white boxes are realized Danish liberalization milestones [1, 2].

Based on this overview, five primary railway timetable stakeholders have been identified: Passenger TOC DSB and Arriva, largest freight TOC DB Schenker Rail Services Scandinavia, IM Rail Net Denmark (Banedanmark in Danish) and The Danish Transport Authority (Trafikstyrelsen in Danish).

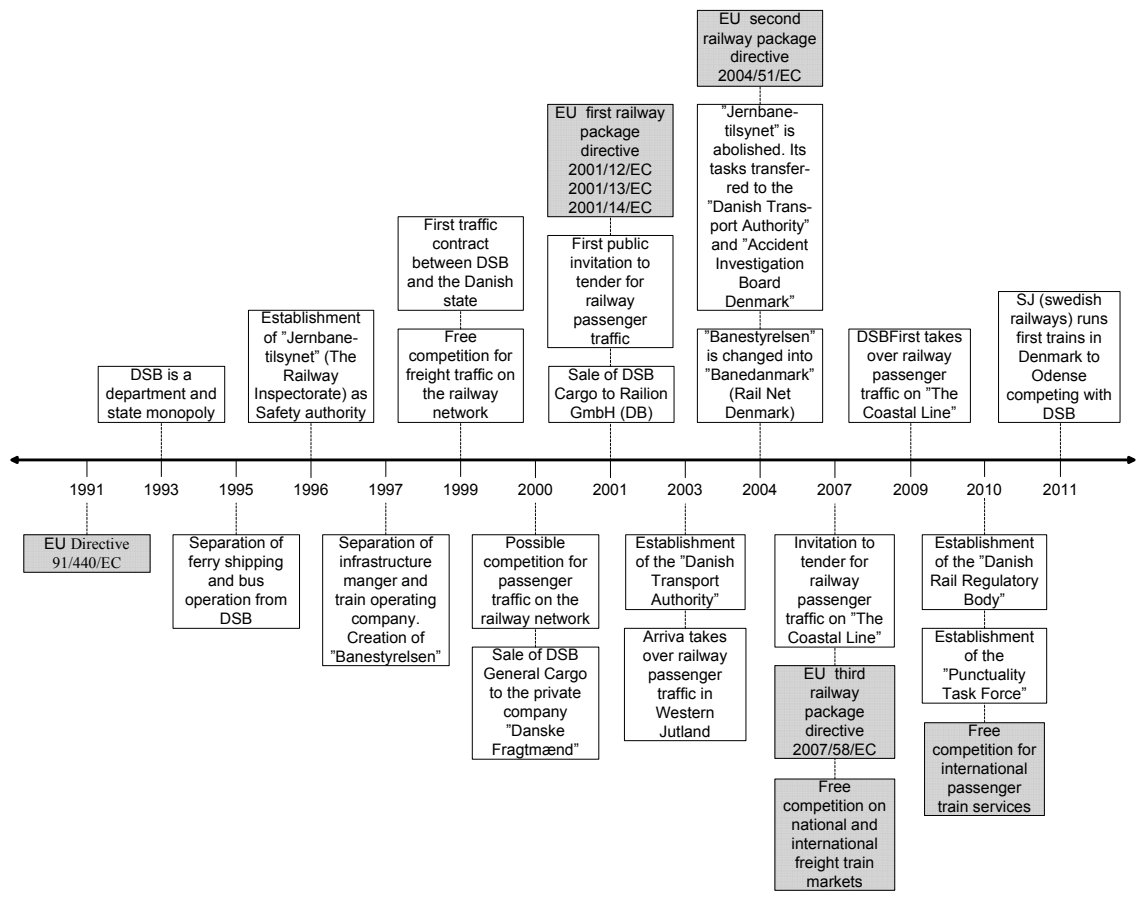

Figure 1: Liberalization timeline for the Danish railway sector [1, 2].

Each stakeholder was interviewed and the result of each interview was a company list of five prioritized railway timetable evaluation criteria. This is presented in section 2. The results from the round of interviews formed the basis for a timetabling criteria workshop. Here the goal was for the stakeholders to 
agree on a common accepted list of prioritized timetable evaluation criteria. The workshop and its results are presented in section 3. With the results from the workshop it is possible to propose a revision of the current timetabling process to ensure the application of the found timetabling criteria. A revised timetabling process is presented in section 4. A discussion of the achieved results during this working process takes places in section 5 . Conclusions and future perspectives are presented in section 6 .

\section{Interviews with railway timetable stakeholders}

These interviews took place at the offices of the stakeholders or over the phone (Arriva). First the interviewees were to come up with five timetable evaluation criteria. At some interviews this was done in a brain storming fashion, at others the interviewees had given this some thought beforehand and presented a more or less prepared list of criteria.

Table 1: Overview of results from interviews with railway timetable stakeholders.

\begin{tabular}{|c|c|c|}
\hline \multicolumn{3}{|c|}{ Prioritized stakeholder timetable evaluation criteria } \\
\hline TOC DSB & TOC Arriva & \begin{tabular}{|c|} 
TOC DB Schenker \\
\end{tabular} \\
\hline $\begin{array}{l}\text { 1. Robustness of the } \\
\text { timetable } \\
\text { 2. Fast, high frequent } \\
\text { and direct services } \\
\text { 3. Possibility for } \\
\text { services calling at } \\
\text { smaller stations } \\
\text { 4. Efficient use of } \\
\text { railway infrastructure } \\
\text { 5. Scalability of the } \\
\text { timetable }\end{array}$ & 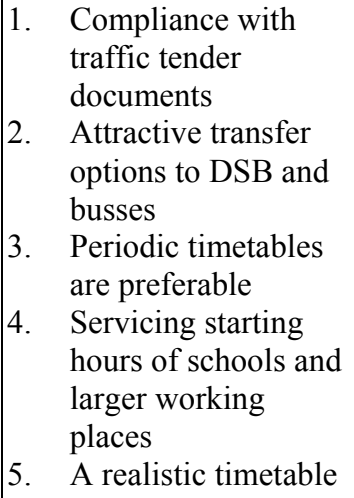 & 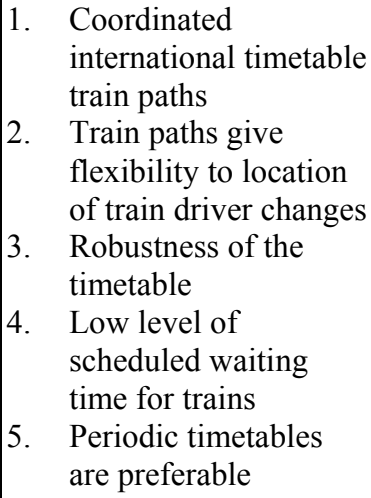 \\
\hline IM Rail Net Denmark & $\begin{array}{c}\text { The Danish Transport } \\
\text { Authority }\end{array}$ & \\
\hline $\begin{array}{l}\text { 1. Robustness of the } \\
\text { timetable } \\
\text { 2. Complexity of traffic } \\
\text { in and around larger } \\
\text { stations } \\
\text { 3. Utilization of } \\
\text { timetable train paths } \\
\text { 4. Travel time for trains } \\
\text { 5. The timetable is } \\
\text { prepared within } \\
\text { given deadline }\end{array}$ & $\begin{array}{ll}\text { 1. } & \begin{array}{l}\text { A periodic timetable } \\
\text { is preferable }\end{array} \\
\text { 2. } & \begin{array}{l}\text { Robustness of the } \\
\text { timetable }\end{array} \\
\text { 3. } & \begin{array}{l}\text { Attractive transfer } \\
\text { options }\end{array} \\
\text { 4. } & \text { Travel time for trains } \\
\text { 5. A reserve of freight } \\
\text { train timetable train } \\
\text { paths }\end{array}$ & \\
\hline
\end{tabular}


Following this the interviewees were asked to give a detailed description of the criteria both to avoid misunderstandings and to make the criteria operational and thereby detectable in a given timetable. Finally the interviewees had to rank their selected five criteria according to importance. Table 1 gives an overview of the results from the held five interviews. A more detailed description of the criteria is given in [3].

The results from the individual stakeholder interviews were given further processing to get a better overview of the achieved results. Some criteria could be grouped under the same overall timetabling topic and others were unique. Table 2 shows the synthesized results from the interviews. Additionally a simple

Table 2: $\quad$ Synthesized overview of interview results and prioritization of criteria.

\begin{tabular}{|c|c|c|c|c|c|c|}
\hline Timetable evaluation criterion & $\begin{array}{c}\text { Rail Net } \\
\text { Denmark }\end{array}$ & DSB & Arriva & $\begin{array}{c}\text { DB } \\
\text { Schenker } \\
\text { Rail }\end{array}$ & $\begin{array}{c}\text { Danish } \\
\text { Transport } \\
\text { Authority }\end{array}$ & $\begin{array}{l}\text { Prioritization } \\
\text { points }\end{array}$ \\
\hline $\begin{array}{l}\text { Robustness of timetable } \\
\text { - Complexity of traffic } \\
\text { in/around stations } \\
\text { - Reserve freight train timetable } \\
\text { train paths }\end{array}$ & $\begin{array}{l}1 \\
2 \\
-\end{array}$ & $\begin{array}{l}1 \\
-\end{array}$ & $\begin{array}{l}5 \\
-\end{array}$ & $\begin{array}{l}3 \\
- \\
-\end{array}$ & $\begin{array}{l}2 \\
- \\
5\end{array}$ & $\begin{array}{l}18 \\
4 \\
1\end{array}$ \\
\hline $\begin{array}{l}\text { Efficient use of infrastructure } \\
\text { - Low level of scheduled } \\
\text { waiting time } \\
\text { - Capacity consumption of } \\
\text { infrastructure } \\
\text { - Attractive transfer options for } \\
\text { trains and busses } \\
\text { - Fast, high frequent and direct } \\
\text { connections }\end{array}$ & $\begin{array}{l}4 \\
3 \\
- \\
-\end{array}$ & $\begin{array}{l}4 \\
- \\
- \\
-\end{array}$ & $\begin{array}{l}- \\
- \\
2 \\
-\end{array}$ & $\begin{array}{l}4 \\
- \\
- \\
-\end{array}$ & $\begin{array}{l}4 \\
- \\
3 \\
-\end{array}$ & $\begin{array}{l}8 \\
3 \\
7 \\
4\end{array}$ \\
\hline $\begin{array}{l}\text { Periodic timetable is } \\
\text { preferable }\end{array}$ & - & - & 3 & 5 & 1 & 9 \\
\hline $\begin{array}{l}\text { Compliance with traffic } \\
\text { tender demands }\end{array}$ & - & - & 1 & - & - & 5 \\
\hline $\begin{array}{l}\text { Coordinated international } \\
\text { timetable time slots }\end{array}$ & - & - & - & 1 & - & 5 \\
\hline $\begin{array}{l}\text { Timetable train paths give } \\
\text { flexibility to where change of } \\
\text { train driver can take place }\end{array}$ & - & - & - & 2 & - & 4 \\
\hline $\begin{array}{l}\text { Train service for smaller } \\
\text { stations }\end{array}$ & - & 3 & - & - & - & 3 \\
\hline $\begin{array}{l}\text { Servicing starting hours of } \\
\text { schools and larger workplaces }\end{array}$ & - & - & 4 & - & - & 2 \\
\hline Scalability of timetable & - & 5 & - & - & - & 1 \\
\hline $\begin{array}{l}\text { Timetable is prepared within } \\
\text { given deadline }\end{array}$ & 5 & - & - & - & - & 1 \\
\hline
\end{tabular}


attempt has been made to get a first picture of the overall ranking of identified criteria by using a concept of prioritization points, based on the stakeholder made prioritizations. A top priority gives five points and a fifth priority gives one point. The by far highest point score, with 18 points, is achieved by the criterion "robustness of the timetable". This is followed by "periodic timetables are preferable" with 9 points, "efficient use of infrastructure" with 8 points and "capacity consumption of infrastructure" with 7 points. Rank five is shared between "compliance with traffic tender documents" and "coordinated international timetable train paths" with 5 points.

The output from the stakeholder interviews formed the basis for the following timetabling criteria workshop. Here all stakeholders would meet and hopefully agree on a common list of railway timetable evaluation and optimization criteria.

\section{Timetable criteria workshop}

Figure 2 gives an overview of the overall workshop process. The stakeholder lists of prioritized timetabling criteria formed the basic input for the workshop, which should lead to a common accepted list of timetable evaluation criteria.

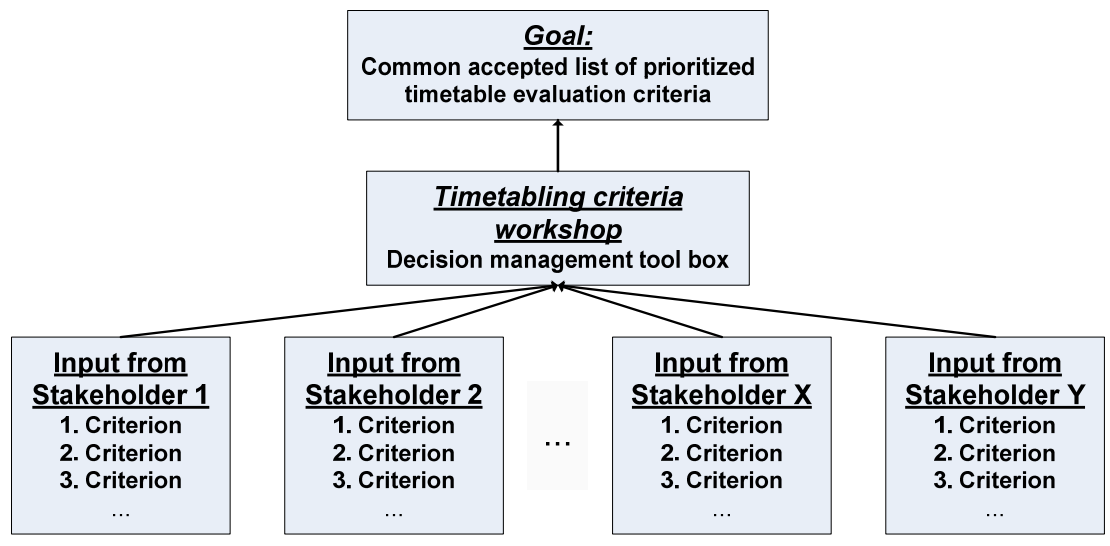

Figure 2: Timetabling criteria workshop process.

A condensed version of the timetabling criteria workshop agenda can be seen in figure 3. Unfortunately, a last minute cancellation was received by Arriva, who stated that their interests would be covered by DSB! All other stakeholder participated. There were several changes in company representatives. An overview is given in table 3. Amongst the participants of the workshop there was consensus about that Arriva's list of prioritized timetabling criteria should be presented. This was done without any stakeholder comments.

While presenting the first list of prioritized timetabling criteria, it became apparent that any changes to the criteria lists would be made during the presentations and not after all lists had been presented. 
Table 3: Company representatives for interviews and the timetabling criteria workshop.

\begin{tabular}{|c|c|c|}
\hline \multirow{2}{*}{ Company } & \multicolumn{2}{|c|}{ Representatives } \\
\hline & Workshop & Interview \\
\hline DSB & $\begin{array}{l}\text { Lars Christian Krogsdam } \\
\text { Per Elgaard }\end{array}$ & $\begin{array}{l}\text { Niklas Kohl } \\
\text { Per Elgaard }\end{array}$ \\
\hline Arriva Denmark & & Kent Nielsen (by phone) \\
\hline $\begin{array}{l}\text { DB Schenker Rail } \\
\text { Scandinavia }\end{array}$ & $\begin{array}{l}\text { Claus Jensen } \\
\text { Thomas Vestergaard }\end{array}$ & Susanne Olling Nielsen \\
\hline $\begin{array}{l}\text { Danish Transport } \\
\text { Authority }\end{array}$ & $\begin{array}{l}\text { Benny Mølgaard } \\
\text { Claus Jørgensen }\end{array}$ & $\begin{array}{l}\text { Benny Mølgaard } \\
\text { Claus Jørgensen } \\
\text { Jacob Møldrup Petersen }\end{array}$ \\
\hline Rail Net Denmark & $\begin{array}{l}\text { Lasse Toylsbjerg-Petersen } \\
\text { Ib Flod Johansson }\end{array}$ & $\begin{array}{l}\text { Lasse Toylsbjerg-Petersen } \\
\text { Ib Flod Johansson }\end{array}$ \\
\hline
\end{tabular}

1. Presentation of all lists with criteria to all stakeholders

2. Adding/removing criteria if wanted by stakeholders

3. Simple scoring of criteria. Each stakeholder has five votes. One vote for five criteria
4. Ranking and reducing pool of criteria according to their score

5. Individual ranking of remaining criteria. Stakeholders must state arguments

6. Achieving consensus on a prioritized list of criteria

Figure 3: Timetabling criteria workshop agenda.

During these presentations the participants of the workshop by themselves started working on creating a common list of timetable evaluation and optimization criteria from the presented lists of timetabling criteria. This spontaneous deviation from the agenda was not opposed by the author since the dialogue between participants could improve the chances of reaching a reduced list of timetabling criteria based on a consensus rather than the application of the simple ranking methodology often applied within the field of decision management [4].

During this phase of dialogue several questions arose: Such as which criteria are controlled by stakeholders and which are controlled by contractual obligations towards the Danish Ministry of Transport, and what is the length of the periodicity interval in a periodic timetable. The Danish Transport Authority could give answers to the first part and the author to the second part by stating that a periodicity interval could be as little as 10 minutes and as long as 2 hours [5]. It was also decided by the participants to generally use the term "Systematic timetable" as replacement for "Periodic timetable", hereby avoiding the uncertainty in regards to the use of the wording "periodicity intervals of a given timetable".

Following the last presentation of the Danish Transport Authority's list of timetabling criteria, an uncertainty in regards to the difference in socio-economic 
value of "transfer time" and "travel time" arose. It was clarified that a reduction in transfer time is given double the value than the same reduction in travel time. This was as a surprise for several the participants [6].

The representatives from Rail Net Denmark wanted their criterion "Utilization of timetable train paths" renamed to "capacity utilization for a railway line section".

After the presentations there was a general uncertainty amongst the participants about the application of timetabling evaluation and optimization criteria. Since some of the stated criteria are given demands from the Danish Ministry of Transport. The Danish Transport Authority is the link between the ministry and the railway sector and must both fulfill several contractual obligations towards the ministry and must handle the interests of the ministry towards all other railway stakeholders.

Several participants looked at the robust timetable criterion as being a basic precondition and therefore it should always be ensured by the applied planning rules of the IM. The ensuing discussion proved that the uncertainty connected to the timetable robustness criterion originates from the more or less loose definitions within the group of the other timetabling criteria.

This lead to a discussion about the achievability of the workshop goal and it was stated by the author that the goal was to get a snapshot of today's situation and that this kind of workshop should be repeated every time larger changes take place in the preconditions for railway timetabling in Denmark. It then became apparent for all stakeholders, that an intelligent surveillance and evaluation system for railway timetables was needed in the future.

All this lead to that the participants agreed on that the criterion "societal acceptance of the timetable" was missing and must be added to a first version of a common list of timetabling criteria. The reduced list of common accepted timetable evaluation and optimization criteria included the following criteria:

- Attractive transfer options (to other train and bus services)

- Robustness of the timetable

- Societal acceptance of the timetable

- Systematic timetables are preferable (earlier periodic timetables)

- Travel time of trains

- Utilization of capacity on railway line sections

A ranking of these timetabling criteria was the next step. The author decided that the simple ranking methodology would be applied now. Every stakeholder was given three votes and should reward three criteria with one vote each. The criteria were listed on a marker board and the votes were given by sticking postit stickers next to each timetabling criteria. Table 4 shows the result.

The criteria can be placed in three layers with two criteria in each. First rank criteria received three votes each, second rank criteria got two votes and third rank criteria ended up with one vote each.

This approach had not given a unique ranking of criteria. The author asked the participants to rank the two criteria in each layer according to their mutual importance. After a short discussion among the participants, they decided unanimously against ranking the criteria in each layer, since the difference in 
criterion importance was so small. This was accepted by the author and therefore the result of the workshop: The first common Danish list of railway timetable evaluation and optimization criteria can be seen in table 4 .

Table 4: $\quad$ Timetabling criteria and their achieved number of votes.

\begin{tabular}{|l|l|}
\hline Level of importance & Timetable evaluation and optimization criteria \\
\hline High (3 votes) & $\begin{array}{l}\text { Utilization of capacity on railway line sections and } \\
\text { Systematic timetables are preferable }\end{array}$ \\
\hline Medium (2 votes) & $\begin{array}{l}\text { Robustness of timetable are preferable and } \\
\text { Societal acceptance of the timetable }\end{array}$ \\
\hline Low (1 vote) & Travel time of trains and Attractive transfer options \\
\hline
\end{tabular}

\section{Revision of the timetabling process}

Based on the result from the timetabling criteria workshop the timetabling process can be improved. A simplified version of the present timetabling process at IM Rail Net Denmark can be seen in figure 4.

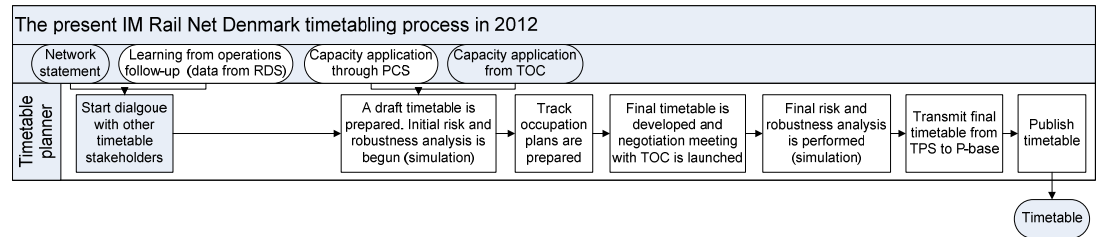

Figure 4: Overview of the present timetabling process at IM Rail Net Denmark.

This process is set up according to EU legislation and guidelines from the professional organization Rail Net Europe (RNE) for European IM [7-9]. First step is to use experience from earlier timetables to improve the future one. Major input comes from the follow-up on run train operations. The RDS-system, punctuality and operations statistics system (in Danish: Regulatitets- og DriftsStatistik), provides the necessary data from realized traffic operations. Other important input comes from IM signal men and the TOC. Second step is to receive the wishes for train operations from TOC in form of capacity applications. Capacity requests from other RNE customers come in through the train path coordination system (PCS). Based on this the timetable planner creates a first draft version of the timetable and an initial robustness analysis is performed. Following this, signal men prepare the detailed track occupation plan for larger stations. A first version of the final timetable is presented to the TOC at a negotiation meeting where minor conflicts between TOC should be solved and minor changes to the timetable can be made. A final robustness analysis of selected parts of the timetable is carried out. Then the timetable is transmitted from the timetable planning system (TPS) to the train traffic production database 
(P-base). Finally the timetable is published, both the public timetable and the working timetable.

Figure 5 gives an overview of the suggested timetabling process at IM Rail Net Denmark in 2020. This is the year were the European signalling and traffic management system ETCS/ERTMS level 2 has been implemented on the entire network of Rail Net Denmark. The timetabling process has the same basic steps as today's process. This is due to EU legislation and RNE guidelines that must be followed. With the common Danish list of railway timetable evaluation and optimization criteria it is possible to develop a series of key performance indicators (KPI) based on the identified criteria. The risk and robustness analysis can now be improved to a risk and attractiveness analysis where a given timetable variant receives a KPI-score on investigated risks and its overall attractiveness in regards to the timetable evaluation criteria. The negotiation meeting and the revision of timetable variants should be part of an iterative process where the goal should be achieve the best KPI-score for the timetable. It is assumed that the future TPS will have much more intelligent functionalities, e.g. OR timetabling algorithms and therefore be far more efficient. This makes it possible to work with several timetable variants during the process rather than only one as is the case today. In the last steps the final timetable is transmitted to the new traffic management system (TMS) and published in a standard data format to increase its availability.

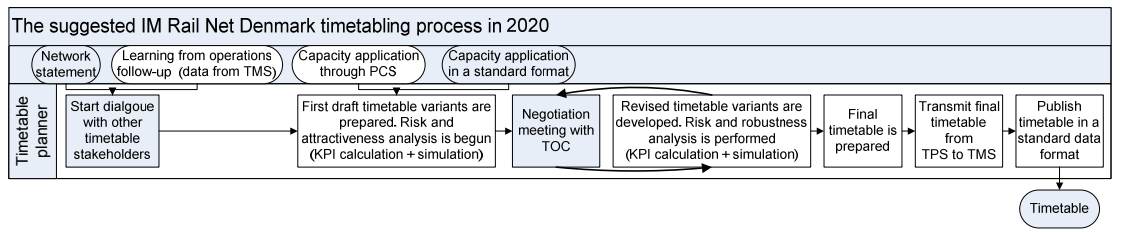

Figure 5: Overview of the suggested timetabling process at IM Rail Net Denmark in 2020.

\section{Discussion}

The Danish railway sector, as any other European railway sector, is much affected by the present political climate. Today's focus and strategy can be completely different next year. This can make it necessary to repeat the process from the timetabling criteria workshop again in a few years. Representatives from the railway sector have to take this kind of specific railway discussions and bring them to the attention of the surrounding society and find out what point of view the society has towards these topics.

The identified criteria should be defined according to a higher level of detail, both qualitatively and quantitatively, to make them more operational. One or several KPI should be derived from each criterion. This might prove straight forward for some criteria and more complex for others. Different opinions were presented at the workshop and this can have made the criteria descriptions and definitions ambiguous. This can make it more difficult to create KPI. 
Almost a year passed between the two events and this had an effect on the workshop. When looking at table 3, big differences between interviewed company people and workshop company representatives can be seen. This missing continuity combined with the long time span could have caused many changes in the prioritized lists of evaluation criteria from the interviews. A substantial prolongation of the first part of the workshop could have been the result and thereby have made workshop progress more difficult. New people bring with them new opinions and this could have lead to bigger disagreements at the workshop.

Table 5 gives an overview of the results achieved with the round of stakeholder interviews and the timetabling criteria workshop. From the round of interviews it was possible to get a specific ranking of the first four criteria. The following two criteria received the same number of prioritization points. At the workshop it was not possible to give individual ranks to the identified timetabling criteria. They were grouped in three ranking layers with two equal important criteria in each layer.

Table 5: Overview of interview and workshop results.

\begin{tabular}{|l|l|l|}
\hline Rank & \multicolumn{1}{|c|}{ Interview criteria } & \multicolumn{1}{c|}{ Workshop criteria } \\
\hline 1 & Robustness of timetable & $\begin{array}{l}\text { Utilization of capacity on } \\
\text { line sections and systematic } \\
\text { timetable }\end{array}$ \\
\hline 2 & Periodic timetable is preferable & $\begin{array}{l}\text { Robustness of timetable and } \\
\text { societal acceptance }\end{array}$ \\
\hline 3 & Low level of scheduled waiting time \\
\hline 4 & $\begin{array}{l}\text { Attractive transfer options for trains } \\
\text { and buses }\end{array}$ & $\begin{array}{l}\text { Compliance with traffic tender } \\
\text { demands and } \\
\text { Coordinated international timetable } \\
\text { train paths }\end{array}$ \\
\hline 5 & $\begin{array}{l}\text { Train travel time and } \\
\text { attractive transfer options }\end{array}$ \\
\hline
\end{tabular}

When looking at the rank one and two criteria, it surprises that only one common criterion can be found in the results: "systematic/periodic timetable". Another surprise is that the criterion "robustness of the timetable" only was ranked third/fourth at the workshop but attained a very clear first rank at the held interviews. Reason for this shift in priority most likely relates to the discussion about assuming that any prepared timetable must be robust. Taking this criterion for granted in all timetables reduces its importance potential. The introduction of the "societal acceptance of the timetable" as an evaluation criterion also reduced the priority potential of the "robustness of timetable" criterion since they due overlap.

The last shared timetabling criterion is "attractive transfer options" This was put in the fifth + sixth rank layer at the workshop but held a fourth rank in the interview results. By introducing the new "societal acceptance of the timetable" criterion during the workshop, the "attractive transfer options" criterion was 
pushed down to a lower workshop priority. Reason for this is again an overlap between the two criteria.

Evaluation criterion "societal acceptance of the timetable" holds many aspects and thereby overlaps with other criteria. If society in general demands a very high service level on the railway network, this will increase the number of running trains. Hereby the capacity consumption on railway line sections increases, as well the complexity of the train path structure in a given timetable. Therefore the risk of train delays gets higher and fewer trains will run on time.

The workshop criterion "utilization of capacity on line sections" is not found directly among the interview criteria. But to be able to have a "low level of scheduled waiting time" the "utilization of capacity on line sections" must follow some rules in regards to the mix of traffic.

TOC Arriva was not present at the workshop and this affected the outcome of the workshop. The top ranking Arriva-interview criterion "compliance with traffic tender demands" is not present in the workshop list of criteria. Rank 2 Arriva criterion "attractive transfer options to other trains and buses" only achieved the third layer of criteria at the workshop.

DB Schenker Rail Scandinavia was present at the workshop but their rank 1 interview timetabling criterion "coordinated international timetable train paths" did not make it to the list of workshop criteria. A complete change in representatives from DB Schenker Rail Scandinavia between the interview and the workshop is most probably the reason for this.

With a common Danish list of railway timetable evaluation and optimization criteria it is only natural to revise the existing timetabling process to take advantage of this new tool. Unfortunately the overall structure of the process cannot be changed due to restrictions from EU legislation and RNE guidelines. By introducing a series of KPI in the analysis/evaluation of a timetable variant, and by formalizing an iterative work step in the timetabling process, future timetables should improve in quality.

\section{Conclusion and perspective}

A first common list of railway timetable evaluation and optimization criteria for the Danish railway sector has been created. It consists of three layers with two equal important timetabling criteria in each:

Rank 1: Utilization of capacity on line sections and systematic timetable;

Rank 2: Robustness of timetable and societal acceptance;

Rank 3: Train travel time and attractive transfer options.

The process of achieving such a list began with a series of five successful interviews with selected railway timetable stakeholders. The stakeholders were: TOC DSB, Arriva, DB Schenker Rail, The Danish Transport Authority and IM Rail Net Denmark. Each interview resulted in a list of five well described and ranked timetabling criteria. The output from these interviews was the starting point for the held timetabling criteria workshop at the Technical University of Denmark. Here all stakeholders, besides TOC Arriva, met and together created the common list of prioritized timetabling criteria. 
This new tool makes it possible to revise the timetabling process at IM Rail Net Denmark. The proposed revision focuses on the introduction of a newly developed set of timetable KPI that are based on the identified timetabling workshop criteria. Timetable variants should both be analyzed in regards to their risks and attractiveness towards the common list of timetabling criteria. Assuming that future TPS are much more intelligent and efficient in the timetable creation process, a more iterative approach to timetable development is introduced in the proposed revised IM timetabling process.

To the question if a process like this should be repeated, the stakeholders answered that it would be interesting to see how things had developed in a few years time. It would be of big advantage if a detailed qualitative and quantitative (KPI) description of the timetabling criteria could be presented at the same time. The quantitative calculations could back up the qualitative description of each timetable evaluation and optimization criterion.

A new quantitative methodology, based on the Danish socio-economic approach, should be developed for the balancing between future passenger and freight railway traffic, when allocating the limited infrastructure capacity. Which configuration of passenger and freight trains should be used and which priority should be given to each train in the timetabling process to achieve the socioeconomic optimum.

\section{References}

[1] Boston Consulting Group, "Øget konkurrenceudsættelse af jernbanesektoren” (in Danish), 2009.

[2] Council Directive 91/400/EEC of 29 July 1991 on the development of the Community's railways (91/440/EEC), Official Journal of the European Communities, No L 237/25.

[3] Schittenhelm, B., "Creation of a Framework for Railway Timetable Optimization Criteria", Proc. of the 4th International Seminar on Railway Operations Modelling and Analysis 2011 (RailRome 2011).

[4] Goodwin P. \& Wright G., "Decision Analysis for Management Judgement" (book, third edition), 2004.

[5] Liebchen, C., Periodic Timetable Optimization in Public Transport, $\mathrm{PhD}$ Thesis, Technical University of Berlin, 2006.

[6] DTU Transport - Department of Transport \& COWI, Transportøkonomiske Enhedspriser - til brug for samfundsøkonomiske analyser (MS Excel-file), version 1.3, 2010 (in Danish).

[7] Directive 2001/14/EC of the European Parliament and of the Council of 26 February 2001 on the allocation of railway infrastructure capacity and the levying of charges for the use of railway infrastructure and safety certification, Official Journal of the European Communities, No L 75/29.

[8] Rail Net Europe, Customer Handbook, version of: 06 February 2006.

[9] Rail Net Europe, RNE Process Handbook for International Path Allocation For Infrastructure Managers, 21 November 2005. 